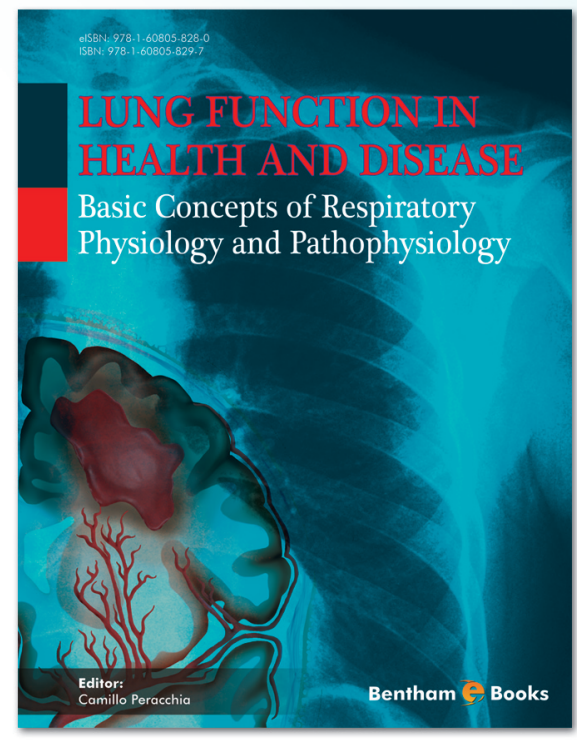

\section{Authors:}

Camillo Peracchia

\& Nasr H. Anaizi

University of Rochester

USA

\title{
Lung Function in Health and Disease
}

\section{Basic Concepts of Respiratory Physiology and Pathophysiology}

\section{Ww.henthamseience.eom/ehooks/9781608058280}

\section{About the ebook}

This reference presents basic concepts relevant to respiratory function in normal and diseased states. The volume stresses a quantitative approach to physical parameters used as indicators of normal and diseased physiological respiratory function. This book is intended for first and second year medical students as well as for residents and fellows, especially in disciplines such as anesthesiology and pulmonary medicine.

\section{Contents}

- Historical Background

- Basic Lung Structure

- Respiratory Mechanics

- Gas Exchange

- Gas Transport

- Acid-Base Balance

- Ventilation-Perfusion Distribution, Blood Shunts and Alveolar Dead Space

- Respiration at Rest and During Exercise at Sea Level and High Altitude

- Functional Consequences of Respiratory Diseases

For Sales and Advertising Inquiries: Contact: marketing@benthamscience.org 